\title{
Energetic particle induced intra-seasonal variability of ozone inside the Antarctic polar vortex observed in satellite data
}

\author{
T. Fytterer ${ }^{1}$, M. G. Mlynczak ${ }^{2}$, H. Nieder ${ }^{1}$, K. Pérot ${ }^{3}$, M. Sinnhuber ${ }^{1}$, G. Stiller ${ }^{1}$, and J. Urban ${ }^{3 \dagger}$ \\ ${ }^{1}$ Institute for Meteorology and Climate Research, Karlsruhe Institute of Technology, Eggenstein-Leopoldshafen, Germany \\ ${ }^{2}$ Atmospheric Sciences Division, NASA Langley Research Center, Hampton, VA, USA \\ ${ }^{3}$ Department of Earth and Space Sciences, Chalmers University of Technology, Göteborg, Sweden \\ $\dagger$ deceased, 14 August 2014
}

Correspondence to: T. Fytterer (tilo.fytterer@kit.edu)

Received: 19 October 2014 - Published in Atmos. Chem. Phys. Discuss.: 11 December 2014

Revised: 19 February 2015 - Accepted: 6 March 2015 - Published: 24 March 2015

\begin{abstract}
Measurements from 2002 to 2011 by three independent satellite instruments, namely MIPAS, SABER, and SMR on board the ENVISAT, TIMED, and Odin satellites are used to investigate the intra-seasonal variability of stratospheric and mesospheric $\mathrm{O}_{3}$ volume mixing ratio (vmr) inside the Antarctic polar vortex due to solar and geomagnetic activity. In this study, we individually analysed the relative $\mathrm{O}_{3}$ vmr variations between maximum and minimum conditions of a number of solar and geomagnetic indices (F10.7 $\mathrm{cm}$ solar radio flux, Ap index, $\geq 2 \mathrm{MeV}$ electron flux). The indices are 26-day averages centred at 1 April, 1 May, and 1 June while $\mathrm{O}_{3}$ is based on 26-day running means from 1 April to 1 November at altitudes from 20 to $70 \mathrm{~km}$. During solar quiet time from 2005 to 2010, the composite of all three instruments reveals an apparent negative $\mathrm{O}_{3}$ signal associated to the geomagnetic activity (Ap index) around 1 April, on average reaching amplitudes between -5 and $-10 \%$ of the respective $\mathrm{O}_{3}$ background. The $\mathrm{O}_{3}$ response exceeds the significance level of $95 \%$ and propagates downwards throughout the polar winter from the stratopause down to $\sim 25 \mathrm{~km}$. These observed results are in good qualitative agreement with the $\mathrm{O}_{3} \mathrm{vmr}$ pattern simulated with a threedimensional chemistry-transport model, which includes particle impact ionisation.
\end{abstract}

\section{Introduction}

Energetic particles ( $\mathrm{keV}-\mathrm{MeV})$, mainly originating from the sun but also from the Earth's magnetospheric radiation belts and the aurora region, penetrate the atmosphere down to mesospheric and stratospheric regions, depending on their energy. The particles are guided by the Earth's magnetic field lines and therefore mostly precipitate at auroral and radiation belt areas $\left(\sim 55-70^{\circ}\right.$ geomagnetic latitudes $)$, depositing energy and directly influencing the chemical composition of the stratosphere and mesosphere. Due to the air compounds, precipitating particles mainly produce large abundances of $\mathrm{O}_{2}^{+}$ as well as $\mathrm{N}\left({ }^{2} \mathrm{D}\right)$ and $\mathrm{N}_{2}^{+} \cdot \mathrm{N}\left({ }^{2} \mathrm{D}\right)$ and $\mathrm{N}_{2}^{+}$lead to increased concentrations of odd nitrogen $\left(\mathrm{NO}_{\mathrm{x}}=\mathrm{N}+\mathrm{NO}+\mathrm{NO}_{2}\right)$ through a number of reactions, including dissociative recombination of $\mathrm{N}_{2}^{+}$and ion-neutral chemistry with species of the oxygen family (e.g. Rusch et al., 1981). Additionally, $\mathrm{O}_{2}^{+}$and water vapour initialise chain reactions associated with water cluster ion formation and accompanied recombination reactions, which eventually lead to the production of odd hydrogen $\left(\mathrm{HO}_{\mathrm{x}}=\mathrm{H}+\mathrm{OH}+\mathrm{HO}_{2}\right.$; e.g. Solomon et al., 1981).

Both $\mathrm{HO}_{\mathrm{x}}$ and $\mathrm{NO}_{\mathrm{x}}$ play an important role in destroying $\mathrm{O}_{3}$ in the mesosphere and stratosphere (e.g. Lary, 1997). However, $\mathrm{HO}_{\mathrm{x}}$ is short-lived (seconds-hours) and therefore more important near its source region in the mesosphere, while $\mathrm{NO}_{\mathrm{x}}$ has a relatively long lifetime (days-months), at least during night-time conditions. Consequently, $\mathrm{NO}_{\mathrm{x}}$ can be transported downwards inside the polar vortex (e.g. Solomon et al., 1982) from the upper mesosphere/lower thermosphere down to the stratosphere, resulting in stratospheric 
$\mathrm{O}_{3}$ depletion through catalytic chemical reactions in combination with solar radiation. Thus, energetic particle precipitation (EPP) indirectly affects $\mathrm{O}_{3}$ during polar winter. Since $\mathrm{O}_{3}$ is the major radiative heating source in the stratosphere, variations of this gas will also influence the stratospheric temperature field and eventually lead to altered atmospheric dynamics. However, the atmospheric response to EPP is not fully understood so far. The current knowledge is discussed in more detail by Sinnhuber et al. (2012).

Observations of the EPP indirect effect on stratospheric polar $\mathrm{O}_{3}$ are relatively rare, at least compared to other latitudes, due to a lack of long-term $\mathrm{O}_{3}$ measurements in these regions. However, a hint for this mechanism was presented by Randall et al. (1998) which analysed the Polar Ozone and Aerosol Measurement instrument data, revealing a close anticorrelation between $\mathrm{NO}_{2}$ and $\mathrm{O}_{3}$ mixing ratios in winter/spring from 1994 to 1996 in the Antarctic stratosphere $(\sim 25-35 \mathrm{~km})$. They suggested that the relationship cannot originate from downwards transported $\mathrm{O}_{3}$-deficient air but is due to photochemical destruction of $\mathrm{O}_{3}$ by $\mathrm{NO}_{2}$. Further observations from several satellite instruments from 1992 to 2005 show that the stratospheric $\mathrm{NO}_{\mathrm{x}}$ enhancement in the Southern Hemisphere is caused by EPP (Randall et al., 2007). More recent satellite observations from 2002 to 2012 reported by Funke et al. (2014) reveal that particle induced $\mathrm{NO}_{\mathrm{x}}$ is indeed transported downwards to the middle stratosphere at polar latitudes, while further model studies suggest that the subsiding of $\mathrm{NO}_{\mathrm{x}}$ leads to strongly reduced stratospheric $\mathrm{O}_{3}$ concentrations $(\sim 30 \%)$ down to altitudes $\sim 30 \mathrm{~km}$ (e.g. Reddmann et al., 2010). Thus, it appears promising to search for a link between EPP and $\mathrm{O}_{3}$ in actual data sets, because the downwards propagating signal of the EPP indirect effect on stratospheric and mesospheric $\mathrm{O}_{3}$ throughout the polar winter has not been explicitly observed so far. Note that $\mathrm{NO}_{\mathrm{x}}$ can be only transported downwards inside a stable large-scale dynamical structure, which provides sufficient subsidence and prevents $\mathrm{NO}_{\mathrm{x}}$ removal/dilution by horizontal transport. These conditions are found primarily inside the Antarctic polar vortex, because the Arctic vortex is strongly disrupted by planetary waves, leading to its weakening or temporary breakdown. This large dynamical variability eventually causes high variations in $\mathrm{O}_{3}$ volume mixing ratios (vmr), superposing the EPP indirect effect.

Therefore our study is focused on $\mathrm{O}_{3}$ vmr observations inside the Antarctic polar vortex from $\sim 20-70 \mathrm{~km}$, derived from environmental satellite/Michelson Interferometer for passive atmospheric sounding (ENVISAT/MIPAS), thermosphere ionosphere mesosphere energetics and dynamics/sounding of the atmosphere using broadband emission radiometry (TIMED/SABER), and Odin/sub-millimetre radiometer (SMR) measurements. The intra-seasonal variability of the $\mathrm{O}_{3}$ vmr values has been investigated and the relation to a number of solar and geomagnetic indices, namely the $\mathrm{F} 10.7 \mathrm{~cm}$ solar radio flux, the Ap index, and the $\geq 2 \mathrm{MeV}$ electron flux is analysed.

\section{Data analysis and numerical modelling}

\subsection{Approximation of the Antarctic polar vortex}

The position and the extension of the Antarctic polar vortex were estimated by using the gradient of the potential vorticity (PV) on isentropic surfaces (Nash et al., 1996). Assuming a dry atmosphere at altitudes $\geq 20 \mathrm{~km}$, the PV was calculated from temperature, pressure, relative vorticity, and the corresponding latitude taken from ERA-Interim (https: //ecaccess.ecmwf.int/ecmwf), the latest version of global atmospheric reanalysis data produced by the European Centre for Medium-Range Weather Forecasts (ECMWF). The reference pressure was set to $1000 \mathrm{hPa}$ and the gravitational constant was considered to be dependent on latitude and height. The PV was calculated for all height intervals between 20 and $70 \mathrm{~km}$ which were adapted from the MIPAS retrieval grid (see Sect. 2.2.1). Note that ERA-Interim data are primarily model-driven at mesospheric altitudes but the individual PV results look reasonable at each height interval. As an example, Fig. 1 shows the PV, depending on time and equivalent latitude (EQL), during the Antarctic winter 2011 at $\sim 40 \mathrm{~km}$. The EQLs assigned to an individual PV isoline enclose the same area as the geographical latitudes of equivalent values. However, this area is located around an estimate of the vortex centre position, rather than around the geographical pole. In general, the EQL of the strongest PV gradient indicates the estimated location of the vortex edge; however, in most cases, there are at least two locations revealing gradients of similar magnitude. Therefore, Nash et al. (1996) also considered the zonal wind to locate the real vortex edge, but here we added a visual analysis instead of the zonal wind to divide the Southern Hemisphere into three non-overlapping zones: deep inside the Antarctic polar vortex (CORE) and the corresponding outermost edge (EDGE), covering all EQLs poleward of the respective borders, as well as an area not influenced by the vortex (OUTSIDE), which extends from the equator to the respective OUTSIDE border. In this study we will consider the EDGE region as the Antarctic vortex area, but the CORE and OUTSIDE region are still necessary to determine whether the observed features inside the EDGE zone are actually originating from the vortex itself. The limits of the three regions of each height interval revealed no strong variation from 2002 to 2011, therefore holding for every winter (Table 1). Note that the ECMWF ERA-Interim data only cover heights up to $\sim 63 \mathrm{~km}$. However, considering the behaviour of the Antarctic vortex at altitudes between 60 and $70 \mathrm{~km}$ (Preusse et al., 2009, their Fig. 2a), it seems reasonable to assume that the estimated limits of the three regions at $\sim 63 \mathrm{~km}$ are also valid up to $70 \mathrm{~km}$. 
Table 1. Limits, derived from the potential vorticity $\left(10^{-6} \mathrm{~K} \mathrm{~m}^{2} \mathrm{~s}^{-1} \mathrm{~kg}^{-1}\right)$, of the southern hemispheric regions CORE, EDGE, and OUTSIDE at the individual heights. The altitudes are adapted from the MIPAS retrieval grid and the shown potential vorticity values hold for 2002-2011.

\begin{tabular}{rrrrrrrr}
\hline $\begin{array}{r}\text { Nominal } \\
\text { height }(\mathrm{km})\end{array}$ & CORE & EDGE & $\begin{array}{r}\text { OUT- } \\
\text { SIDE }\end{array}$ & $\begin{array}{r}\text { Nominal } \\
\text { height }(\mathrm{km})\end{array}$ & CORE & EDGE & $\begin{array}{r}\text { OUT- } \\
\text { SIDE }\end{array}$ \\
\hline 20 & -60 & -50 & -30 & 37 & -3600 & -1900 & -1000 \\
21 & -70 & -50 & -30 & 38 & -6000 & -2500 & -1500 \\
22 & -90 & -70 & -40 & 39 & -6000 & -3000 & -2000 \\
23 & -150 & -90 & -40 & 40 & -9000 & -3500 & -2000 \\
24 & -200 & -100 & -60 & 41 & -9000 & -4000 & -2000 \\
25 & -180 & -110 & -60 & 42 & -9000 & -4000 & -2000 \\
26 & -280 & -160 & -100 & 43 & -15000 & -5000 & -3000 \\
27 & -360 & -220 & -120 & 44 & -15000 & -5500 & -3000 \\
28 & -600 & -250 & -120 & 46 & -22000 & -8000 & -4000 \\
29 & -900 & -300 & -150 & 48 & -18000 & -10000 & -2000 \\
30 & -800 & -400 & -200 & 50 & -36000 & -12000 & -4000 \\
31 & -1000 & -400 & -200 & 52 & -32000 & -16000 & -4000 \\
32 & -1600 & -600 & -300 & 54 & -36000 & -16000 & -4000 \\
33 & -2000 & -800 & -400 & 56 & -60000 & -30000 & -5000 \\
34 & -1800 & -1100 & -400 & 58 & -60000 & -30000 & -10000 \\
35 & -2800 & -1400 & -800 & 60 & -60000 & -30000 & -10000 \\
36 & -4000 & -1600 & -1000 & $62-70$ & -180000 & -90000 & -30000 \\
\hline
\end{tabular}

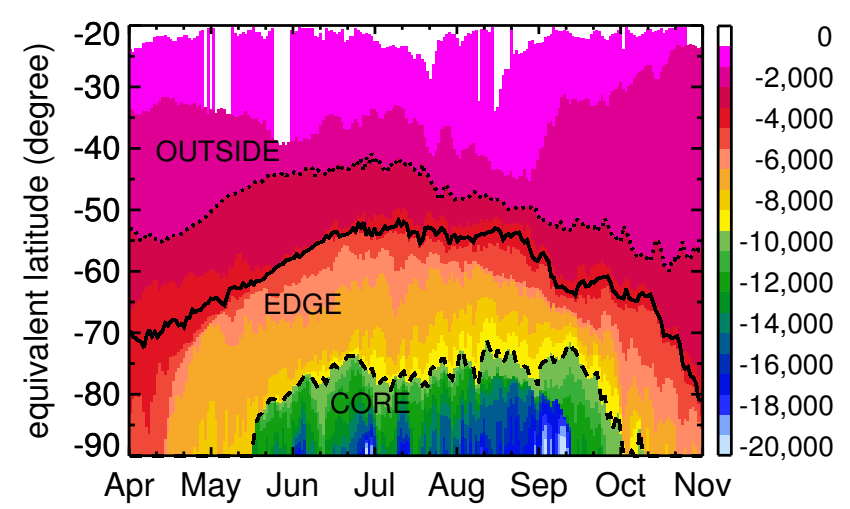

Figure 1. Potential vorticity $\left(10^{-6} \mathrm{~K} \mathrm{~m}^{2} \mathrm{~s}^{-1} \mathrm{~kg}^{-1}\right.$, colour scale) at $\sim 40 \mathrm{~km}$ during the Antarctic winter 2011 as a function of time and equivalent latitude. The thresholds of the regions OUTSIDE (dotted line), EDGE (solid line) and CORE (dashed line) are included. Potential vorticity was calculated from ECMWF Era-Interim data.

\subsection{Ozone measurements}

\subsubsection{MIPAS}

MIPAS (Fischer et al., 2008) was a limb sounder on board ENVISAT, which had a sun-synchronous orbit. The main advantages of MIPAS measurements are the global coverage from $87^{\circ} \mathrm{S}$ to $89^{\circ} \mathrm{N}$ and the availability of observations during both day and night, crossing the equator at $\sim$ 10:00 LT and $\sim$ 22:00 LT, respectively. MIPAS was a Fourier transform infrared (4.15-14.6 $\mu \mathrm{m})$ emission spectrometer, allowing simultaneous observations of several atmospheric trace gases, including $\mathrm{O}_{3}$. MIPAS was operational from July 2002 to April 2012, but due to an instrument failure in March 2004, the entire observation period is divided into two subintervals from July 2002 to March 2004 and January 2005-April 2012 (referred to as P1 and P2 here, respectively). During P1 an almost continuous time series is available, while larger data gaps are present during P2 before October 2006. Here, we use the complete data set of the most frequent observation mode (nominal mode), covering the altitudes from the upper troposphere up to $\sim 70 \mathrm{~km}$ at the poles which was derived from the MIPAS level-2 research processor developed by IMK/IAA. Details of the retrievals are described in von Clarmann et al. (2003), Glatthor et al. (2006), and von Clarmann et al. (2009). Note that the number of tangent heights is constant during P1 (17) and P2 (23), and that the actually available altitudes (cloud contaminated observations are disregarded) only slightly differ from day to day. The corresponding vertical resolution becomes coarser at higher altitudes (independent of the geographical location), increasing from 3.5 to $8 \mathrm{~km}$ (Steck et al., 2007) and from 2.5 to $5 \mathrm{~km}$ (Eckert et al., 2014) in P1 and P2, respectively. However, the retrieval grid in all MIPAS $\mathrm{O}_{3}$ data versions used here (V3O_O3_9, V5R_O3_220, V5R_O3_221) is independent of the tangent heights, with a grid width of $1 \mathrm{~km}$ below 44 and $2 \mathrm{~km}$ above. During P1/P2 $\mathrm{O}_{3}$ was measured at two different wavelength intervals, ranging from 9.0-9.4/9.6-9.7 $\mu \mathrm{m}$ and $12.5-13.5 / 12.7-13.2 \mu \mathrm{m}$ in particular. However, the full spectral ranges were not used, but sub-intervals (microwindows). These were selected to minimise the computing time and to optimise the relation between the measurement-noise induced random error and other errors. These other errors 
originate, among further error sources, from spectral contributions of further atmospheric constituents of unknown abundances. It should also be noted that there is a bias in MIPAS $\mathrm{O}_{3}$ data between the two periods, which was estimated using a multi-linear parametric trend model (Eckert et al., 2014). To accept an $\mathrm{O}_{3}$ data point, the recommended filter criteria for MIPAS $\mathrm{O}_{3}$ data were applied by using an averaging kernel diagonal value $>0.03$ as well as the visibility flag equal to 1 which indicates spectral available data.

At least 10 accepted data points inside the Antarctic polar vortex at a certain grid level were required to calculate the arithmetic average of one day, while at least 13 days were arithmetically averaged to a 26-day running mean from 1 April to 1 November, repeating this algorithm for each height interval and all years from 2002 to 2011 . The time interval of 26 days was chosen to minimise a possible influence of the 27-day cycle of the sun, also ensuring that each time interval includes only one 27-day solar rotation maximum at most. The analysis was repeated for $\mathrm{NO}_{2}$ (V5R_NO2_220, V5R_NO2_221) and the corresponding retrieval is described in Funke et al. (2005 and 2011).

\subsubsection{SABER}

The SABER instrument on board the TIMED Satellite has been nearly continuously operating since January 2002, measuring vertical profiles of several atmospheric parameters and minor constituents (e.g. $\mathrm{O}_{3}$ ) from the surface up to altitudes $>100 \mathrm{~km}$. The SABER measurements are governed by a periodic quasi 60-day cycle, each time changing from the Southern Hemisphere mode $\left(83^{\circ} \mathrm{S}-52^{\circ} \mathrm{N}\right)$ to the Northern Hemisphere mode $\left(52^{\circ} \mathrm{S}-83^{\circ} \mathrm{N}\right)$ and vice versa. Note that the "switching day" is only varying a few days from year to year. To consider both day and night $\mathrm{O}_{3}$ observations, SABER Level 2A Ozone96 data v2.0 and v1.07 (http: //saber.gats-inc.com/custom.php, Rong et al., 2009) measured at $\sim 9.6 \mu \mathrm{m}$ are used. However, v1.07 was only used to fill v2.0 data gaps, which seemed reasonable because the data fit quite well the results of the performed analysis during the respective periods (15-31 May, 7-31 August, not shown here). Consequently, the combined data set of both versions shows no larger data gap and the measurements of both versions were restricted to values $<20 \mathrm{ppm}$ to exclude outliers. Comparisons with the results of an increased threshold to $<100 \mathrm{ppm}$ revealed only minor differences (not shown here). The investigated height interval, ranging from 20 to $70 \mathrm{~km}$, is divided in 38 non-overlapping subintervals and binned at the same altitudes as MIPAS data. The algorithm used to calculate the running means is also identical to the one applied for the "accepted" MIPAS data points. However, SABER needs approximately 60 days to cover all local times, leading to a quasi 60-day wave like oscillation in $\mathrm{O}_{3}$ if 26-day running means are used. This behaviour becomes evident at altitudes $>50 \mathrm{~km}$, where the averaging interval was consequently ex- tended from 26 to 60 days. Note that the calculation of the 60 -day running means required at least 30 days.

\subsubsection{SMR}

The Odin satellite mission started in February 2001 and is a joint project between Sweden, Canada, France and Finland (Murtagh et al., 2002). Odin was launched into a sun-synchronous polar orbit, carrying the SMR instrument and nominally covering the latitude range from $82.5^{\circ} \mathrm{S}$ to $82.5^{\circ} \mathrm{N}$. The SMR makes vertical profile measurements during both day and night, while passing the equator at $\sim$ 06:00/18:00 LT in the descending/ascending node. The $\mathrm{O}_{3}$ data were extracted from the Odin/SMR Level 2 data product, version 2.0 (http://odin.rss.chalmers.se/, Urban et al., 2005), only using measurements of the frequency band centred around $\sim 544.6 \mathrm{GHz}$, providing vertical $\mathrm{O}_{3}$ profiles in the $\sim 15-70 \mathrm{~km}$ altitude range. The filtering criterion used for SMR is the measurement response, which corresponds to the sum of the rows of the averaging kernel matrix. The profiles characterised by a measurement response lower than 0.9 are not reliable enough, and are therefore excluded. The algorithm to calculate the 26-day running means is identical to the one applied to MIPAS data. Note that Odin/SMR was a two-discipline satellite until April 2007, switching between atmospheric (aeronomy mode) and astronomy observations, and is entirely dedicated to aeronomy since this date. Consequently, measurements in the relevant mode are roughly performed one day out of three before April 2007 and every other day afterwards. However, the calculation of the 26-day running means is still possible because the data gaps occur in a regular way, so they do not essentially worsen the 26-day averages. The vertical resolution of the data version used here is better than $3 \mathrm{~km}$ below $45 \mathrm{~km}$, but increases to 5-6 (50$60 \mathrm{~km})$ and $7-10 \mathrm{~km}(60-70 \mathrm{~km})$, leading to noisy results at altitudes $>50 \mathrm{~km}$ compared to the other two instruments.

\subsection{Solar data and geomagnetic indices}

The data of the indices were obtained from two different websites provided by the National Geophysical Data Center. In detail the flux of the $10.7 \mathrm{~cm}$ radio emission from the sun (F10.7) and the geomagnetic Ap index (Ap), commonly used proxies for solar variation and geomagnetic activity, respectively, were downloaded from http://spidr.ngdc.noaa.gov/spidr/. The $\geq 2 \mathrm{MeV}$ electron flux $(2 \mathrm{MeV})$, including the flux of all electrons with energy levels above $2 \mathrm{MeV}$, was measured by the Geostationary Operational Environmental Satellites (GOES) and the corresponding time series were downloaded from ftp://ftp.ngdc.noaa.gov/STP/SOLAR_DATA/ SATELLITE_ENVIRONMENT/Daily_Fluences/. Note that the $2 \mathrm{MeV}$ data set also considers contamination effects on the electron detectors on the spacecrafts due to protons $>32 \mathrm{MeV}$. Furthermore the $2 \mathrm{MeV}$ data are obtained from 
geostationary satellites which perform in-situ measurements in the radiation belts and consequently do not directly provide observations of precipitating particles. However, it is very likely that there is at least a positive relation between $2 \mathrm{MeV}$ and precipitating relativistic radiation belt particles. Thus, the $2 \mathrm{MeV}$ is not used as a proxy of precipitating particles but as an indicator of the influence from the magnetosphere. Precipitating particle integral fluxes in polar regions are observed by sun-synchronous Polar orbiting Operational Environmental Satellite (POES) detectors and the corresponding data correlate better with geomagnetic indices than the GOES electron fluxes (Sinnhuber et al., 2011). However, the respective measurements of the POES instruments tend to underestimate the fluxes from ground-based observations during weak geomagnetic activity (Rodger et al., 2013). Since this study focus on 2002-2011 and an essential part of this time interval overlaps with low geomagnetic activity, GOES data and Ap are used instead of POES measurements. The time series of all data sets are based on daily values, which were arithmetically averaged to 26-day means centred at 1 April, 1 May, and 1 June. The means were separately calculated for each index for the individual years from 2002 to 2011 ; however, $2 \mathrm{MeV}$ data are only available until 2010 .

\subsection{Numerical modelling}

The three-dimensional chemistry and transport model (3dCTM; Sinnhuber et al., 2012, Appendix 1) used here is based on the Bremen 3dCTM (e.g. Wissing et al., 2010), extending on 47 pressure levels from the tropopause up to the lower thermosphere $(\sim 10-140 \mathrm{~km})$ with a latitude/longitude resolution of $2.5^{\circ} \times 3.75^{\circ}$. The model was recently updated with a variable $\mathrm{H}_{2}$ and $\mathrm{O}_{2}$ distribution, leading to proper $\mathrm{HO}_{\mathrm{x}}$ and consequently night time $\mathrm{O}_{3}$ values at altitudes $>60 \mathrm{~km}$ (see Sect. 1). The 3dCTM is driven by meteorological data obtained from simulations of the three-dimensional dynamical model LIMA (Berger, 2008) and the advection is calculated by applying the second-order moments scheme reported by Prather (1986). In the stratosphere, a family approach for the chemical families: $\mathrm{O}_{\mathrm{x}}\left(\mathrm{O}+\mathrm{O}\left({ }^{1} \mathrm{D}\right)+\mathrm{O}_{3}\right)$, $\mathrm{NO}_{\mathrm{x}}\left(\mathrm{N}+\mathrm{NO}+\mathrm{NO}_{2}\right), \mathrm{HO}_{\mathrm{x}}\left(\mathrm{H}+\mathrm{OH}+\mathrm{HO}_{2}\right), \mathrm{BrO}_{\mathrm{x}}(\mathrm{Br}$ $+\mathrm{BrO}), \mathrm{ClO}_{\mathrm{x}}\left(\mathrm{Cl}+\mathrm{ClO}+2 \mathrm{Cl}_{2} \mathrm{O}_{2}\right)$, and $\mathrm{CHO}_{\mathrm{x}}\left(\mathrm{CH}_{3}+\right.$ $\mathrm{CH}_{3} \mathrm{O}_{2}+\mathrm{CH}_{3} \mathrm{OOH}+\mathrm{CH}_{3} \mathrm{O}+\mathrm{HCO}$ ) is used, but was not used for $\mathrm{O}_{\mathrm{x}}, \mathrm{HO}_{\mathrm{x}}$, and $\mathrm{NO}_{\mathrm{x}}$ in the mesosphere/lower thermosphere region.

In this study the $3 \mathrm{dCTM}$ was used to investigate the impact of precipitating particles on $\mathrm{O}_{3}$ inside the Antarctic polar vortex at altitudes from 20 to $70 \mathrm{~km}$. After a multi-year two-dimensional model spin-up, two simulations from 2003 to 2009 were performed. The first run (base run) does not consider any energetic particles, while the second run (EP run) includes ionisation effects by both protons and electrons, using the ionisation rates provided by the Atmospheric Ionisation Module Osnabrück (AIMOS; Wissing and Kallenrode, 2009). The resulting $\mathrm{NO}_{\mathrm{x}}$ production per created ion pair includes various ionic and neutral reactions depending on the atmospheric background state (Nieder et al., 2014). Simple parameterisations are used for the production of $\mathrm{HO}_{\mathrm{x}}$ (Solomon et al., 1981) and O (Porter et al., 1976). Note that heterogeneous chemistry was not included, which only becomes important during spring in the lower stratosphere. Both model runs considered constant solar minimum conditions $\left(\mathrm{F} 10.7=70 \times 10^{-22} \mathrm{~W} \mathrm{~m}^{-2} \mathrm{~Hz}^{-1}\right)$ to exclude $\mathrm{O}_{3}$ variations due to solar activity. The obtained $\mathrm{O}_{3}$ model results of both runs were separately selected according to the vertical MIPAS retrieval grid for direct comparisons to the observations, repeating the described algorithm to calculate the 26-day running means. Finally, in order to derive the $\mathrm{O}_{3} \mathrm{vmr}$ variations solely originating from precipitating particles, the obtained averages of the base run were subtracted from the corresponding $\mathrm{O}_{3}$ values of the EP run. The results were divided by the arithmetic mean of both runs and eventually multiplied by $100 \%$.

\section{Results and discussion}

\subsection{Satellite observations}

\subsection{1 $\mathrm{O}_{3}$ response from 2002 to 2011}

The 26-day $\mathrm{O}_{3} \mathrm{vmr}$ averages from 2002 to 2011 of each altitude-time interval (1 April-1 November, 20-70 km) were individually grouped into years of high and low index activity. For this purpose the index median of the corresponding time series of the 26-day average of an index (F10.7, Ap, $2 \mathrm{MeV}$ ) centred around 1 April was calculated, only including years of actually available $\mathrm{O}_{3}$ observations. Therefore the median of an index time series works as a threshold, dividing the entire time interval from 2002 to 2011 in years of high (above the median) and low (below the median) index activity. Note that the classification of the years does not only depend on the chosen index, but due to data gaps also on the considered height-time interval as well as the instrument used. Afterwards the arithmetic $\mathrm{O}_{3}$ mean of the years of low index activity was subtracted from the $\mathrm{O}_{3}$ mean of the years of high index activity, eventually dividing this absolute $\mathrm{O}_{3}$ difference by the arithmetic $\mathrm{O}_{3}$ average of the entire observation period and multiplying the results by $100 \%$ for more handy values. Thus the calculated relative $\mathrm{O}_{3}$ difference (referred to as $\mathrm{O}_{3}$ amplitude here) represents the impact of the respective index on the $\mathrm{O}_{3}$ background. To reduce the measurement noise of the individual instruments, the results of all three instruments were merged by simply calculating the arithmetic average but only if the corresponding $\mathrm{O}_{3}$ amplitude of all three instruments was available. Note that due to the major sudden stratospheric warming centred around 27 September (Azeem et al., 2010) the $\mathrm{O}_{3}$ observations from 1 September to 1 November 2002 were excluded. In contrast, the solar proton event in the end of October 2003 (Jackman 


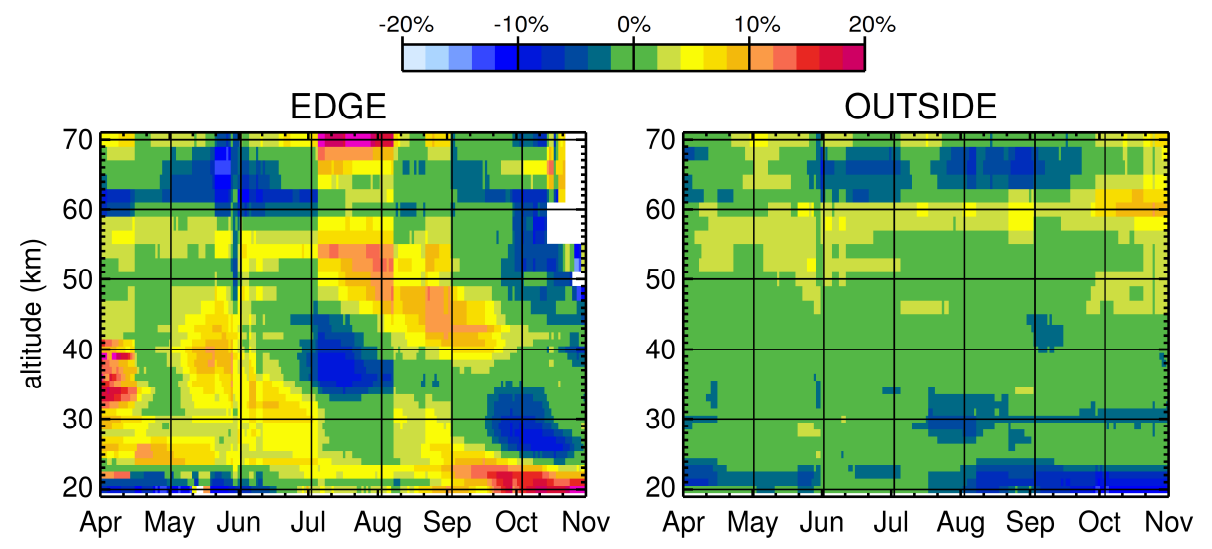

Figure 2. Example of the $\mathrm{O}_{3}$ amplitude (see Sect. 3.1.1 for definition) observed by MIPAS from 2002 to 2011 between years of high Ap index and years of low Ap index centred around 1 April, for the regions EDGE (left) and OUTSIDE (right).

et al., 2005) was neglected due to its late occurrence. The performed analyses with $\mathrm{O}_{3}$ observations, considering the indices from 1 May and 1 June (not shown here), revealed no essential differences compared to 1 April or the structures became less obvious. Comparisons with earlier periods are not reasonable because the vortex first builds up in April. Therefore the focus is set on the $\mathrm{O}_{3}$ response to indices centred around 1 April. The $\mathrm{O}_{3}$ amplitude was calculated for all three regions (CORE, EDGE, and OUTSIDE) which were introduced in Sect. 2.1. The corresponding results reveal that the pattern found inside the EDGE region are fairly similar and less noisy compared to the features observed in the CORE area (not shown here). In contrast the $\mathrm{O}_{3}$ amplitudes outside the Antarctic polar vortex are fundamentally different. An example for the $\mathrm{O}_{3}$ response associated to 1 April Ap in the EDGE and the OUTSIDE region derived from MIPAS measurements is presented in Fig. 2, showing considerably disagreeing structures and essentially weaker amplitudes, especially below $50 \mathrm{~km}$. Thus comparison between the individual regions of the Southern Hemisphere ensures, that, the pattern found in the EDGE region are actually originating from the Antarctic polar vortex.

Figure 3 displays the corresponding results of the $\mathrm{O}_{3}$ amplitude from 2002 to 2011, but only for values above the significance level of $95 \%$ while shaded areas show regions between the significance level of 95 and $99 \%$. The significance was calculated according to a Student's $t$ test, based on the error of the mean of the 26-day running $\mathrm{O}_{3}$ means and assuming the worst case scenario of absolute error propagation. The MIPAS $\mathrm{O}_{3}$ measurements (left column) reveal a high negative response to Ap (upper row) in early Antarctic winter $>60 \mathrm{~km}$, on average ranging around $-10 \%$. Further striking negative $\mathrm{O}_{3}$ amplitudes occur in July between 30 and $40 \mathrm{~km}$ as well as around 1 October at $\sim 30 \mathrm{~km}$, at least weakly indicating the downward transport of the Ap signal in stratospheric $\mathrm{O}_{3}$ due to $\mathrm{NO}_{\mathrm{x}}$ predicted by model studies (e.g. Reddmann et al., 2010). In contrast, a positive $\mathrm{O}_{3}$ am- plitude is found at the beginning of the winter between $\sim 25$ and $\sim 55 \mathrm{~km}(\sim 10-20 \%)$, as well as at altitudes $<30 \mathrm{~km}$ throughout the winter (up to $\sim 20 \%$ in October at $\sim 20 \mathrm{~km}$ ) and above the indicated subsiding layer of negative amplitudes. But considering that most of these features drop below the significance level of $95 \%$ by combining the data of all three instruments (right column), a more detailed investigation of these patterns is not reasonable. However, the results of the merged data set show a well pronounced subsiding negative Ap signal from $\sim 50 \mathrm{~km}$ in June down to $\sim 25 \mathrm{~km}$ in October, which is disrupted in August, while the generally positive structures below $30 \mathrm{~km}$ are also still present.

The $\mathrm{O}_{3}$ response to $2 \mathrm{MeV}$ (middle row) derived from MIPAS observations also indicates a downwelling of negative $\mathrm{O}_{3}$ amplitudes, descending from $\sim 60 \mathrm{~km}$ in June down to $\sim 30 \mathrm{~km}$ in late August. Additionally, the MIPAS $\mathrm{O}_{3}$ response to $2 \mathrm{MeV}$ in early winter is reversed compared to the corresponding influence from $\mathrm{Ap}$ on $\mathrm{O}_{3}$, which does not originate from missing $2 \mathrm{MeV}$ data from 2011. Strong positive $\mathrm{O}_{3}$ amplitudes are generally observed throughout the winter below $30 \mathrm{~km}$, exceeding values of $\sim 20 \%$ in April and October, as well as during October between 30 and $50 \mathrm{~km}$ where the maximum amplitude is lower $(\sim 10 \%)$. The positive features can be validated with the composite results even if they are damped in the region below $30 \mathrm{~km}$. However, this is not the case for the negative response, except for a small area in June in the lower mesosphere. Considering that the Ap responds to lower particle energy levels compared to $2 \mathrm{MeV}$ and that the behaviour of both indices is essentially different from 2002 to 2010 (see Fig. 4), the different $\mathrm{O}_{3}$ amplitudes associated to $\mathrm{Ap}$ and $2 \mathrm{MeV}$ are still reasonable.

The $\mathrm{O}_{3}$ response to F10.7 (lowermost row) is fairly similar between MIPAS and the merged measurements, and both also agree with the respective pattern observed for Ap, including the indicated downwelling of negative $\mathrm{O}_{3}$ amplitudes during midwinter from 50 to $25 \mathrm{~km}$. The composite $\mathrm{O}_{3}$ shows strong positive amplitudes in May $>55 \mathrm{~km}$ which originate 

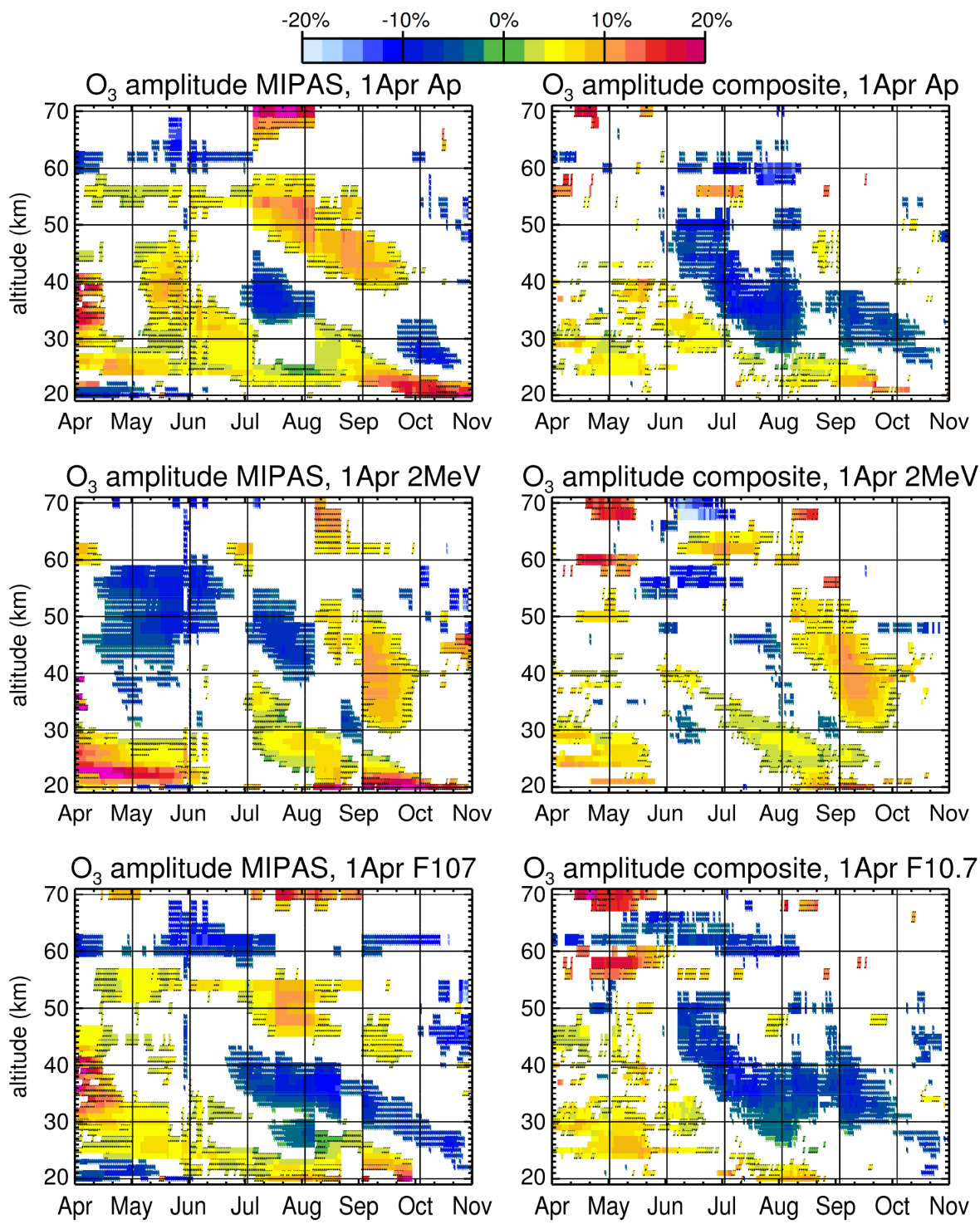

Figure 3. $\mathrm{O}_{3}$ amplitude (see Sect. 3.1.1 for definition) inside the Antarctic polar vortex between years of high index values and years of low index values, namely Ap index (upper row), $\geq 2 \mathrm{MeV}$ electron flux (middle) as well as F10.7 cm solar radio flux (lowermost row) centred around 1 April, derived from MIPAS (left column) and composite (MIPAS+SMR+SABER, right column) observations from 2002 to 2011. Shown are only values above the significance level of $95 \%$. Additionally, regions between the significance level of 95 and $99 \%$ are shaded in black or white, according to a Student's $t$ test.

from SMR measurements and are most likely due to the low vertical resolution of the SMR instrument at these altitudes (see Sect. 2.2.3). The high agreement between the results of $\mathrm{Ap} / \mathrm{O}_{3}$ and $\mathrm{F} 10.7 / \mathrm{O}_{3}$ might originate from the coupling of both indices during solar maximum years (Gray et al., 2010, their Fig. 1). In order to investigate a possible crosscorrelation between solar radiation and geomagnetic disturbances, the analysis was repeated for years of moderate solar activity, only including 2005-2010 (Fig. 4). Similar analyses to extract a more distinct solar signal during times of approximately constant geomagnetic activity were not reasonable, because the respective years of nearly constant Ap values
$(2002,2005,2006,2008,2010)$ do not provide a sufficient amount of data in MIPAS and SMR measurements.

\subsection{2 $\mathrm{O}_{3}$ behaviour during solar minimum activity (2005-2010)}

Figure 5 displays the obtained $\mathrm{O}_{3}$ amplitudes for solar quiet times (2005-2010) associated to 1 April Ap, again only showing values above $95 \%$ significance level and shading the area of regions between 95 and $99 \%$. The MIPAS $\mathrm{O}_{3}$ response to Ap indicates a subsiding negative signal $(\sim-10$ to $-15 \%$ ), starting in late June slightly below $50 \mathrm{~km}$ and prop- 

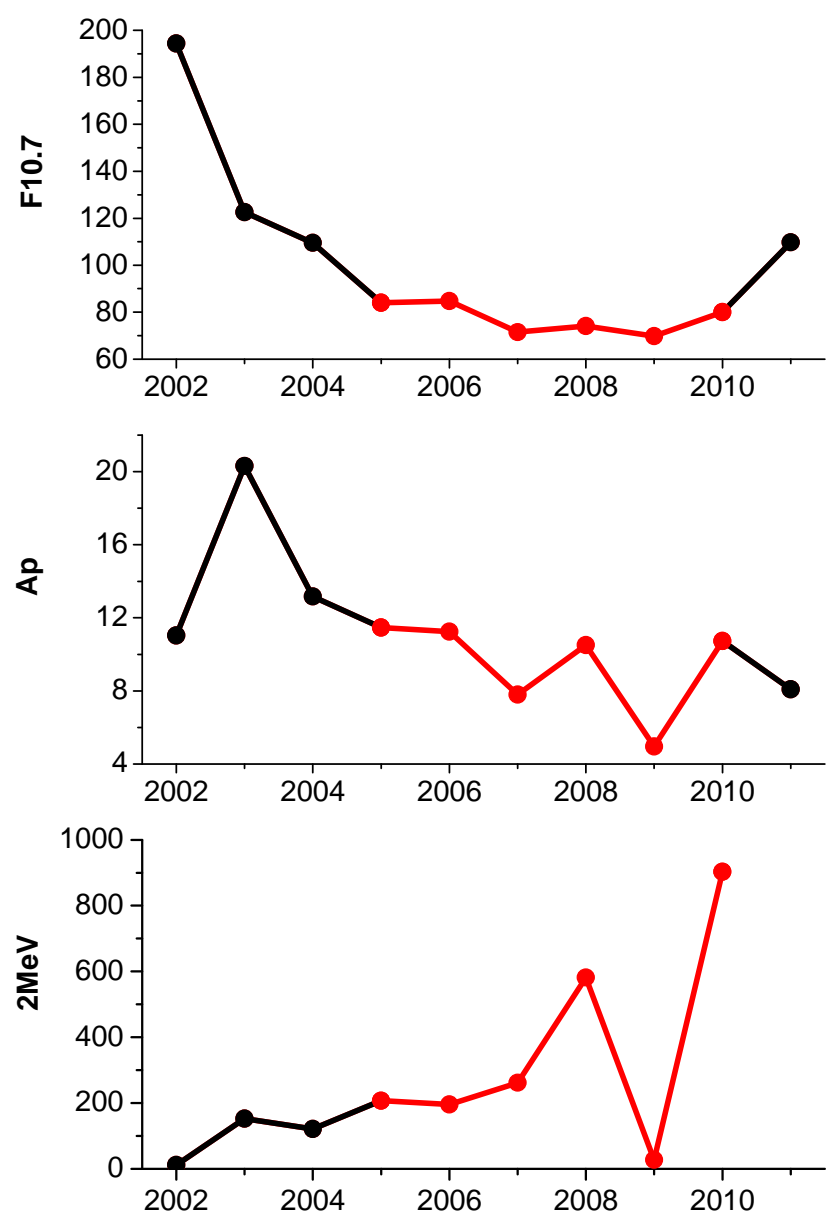

Figure 4. Time series from 2002 to 2011 of the 26-day averages centred around 1 April of the $F 10.7 \mathrm{~cm}$ solar radio flux $\left(10^{-22} \mathrm{~W} \mathrm{~m}^{-2} \mathrm{~Hz}^{-1}\right.$, top), Ap index (middle), and $\geq 2 \mathrm{MeV}$ electron flux (electrons $\mathrm{cm}^{-2} \mathrm{day}^{-1} \mathrm{sr}^{-1}$, bottom). The period of low solar activity from 2005 to 2010 is marked in red. Note the different scaling.

agating downwards to $\sim 25 \mathrm{~km}$ throughout the winter. However, the middle part of the downwelling between late July and late September is below the significance level of $95 \%$ and therefore not shown here. Furthermore, the hinted subsidence is closely surrounded by well pronounced positive $\mathrm{O}_{3}$ amplitudes, especially below $\sim 30 \mathrm{~km}$ which maximise in September (> 20\%). There is also a negative structure centred at 1 June at $\sim 60 \mathrm{~km}$, which cannot be caused by $\mathrm{NO}_{\mathrm{x}}$ but most likely results from $\mathrm{HO}_{\mathrm{x}}$ formation (see Sect. 1). Considering the composite results, the downwelling Ap signal in $\mathrm{O}_{3}$ becomes apparent and robust but slightly weaker $(\sim-10 \%)$ while the positive features are also damped but still present. The mesospheric response is generally weak and the high positive $\mathrm{O}_{3}$ amplitudes in May are again caused by the SMR measurements.

The $2 \mathrm{MeV}$ impact on MIPAS $\mathrm{O}_{3}$ shows generally agreeing features with the influence of the geomagnetic activ- ity and is also of similar magnitude, however, the downwelling negative signal is hinted to already start in late May at $\sim 55 \mathrm{~km}$. In contrast to the $\mathrm{O}_{3}$ response to Ap, the downwards propagating $2 \mathrm{MeV}$ signal is less robust and can be only guessed in the composite $\mathrm{O}_{3}$ amplitude, while the positive structures $(\sim 10-15 \%)$ in August below $30 \mathrm{~km}$ and in September between 30 and $50 \mathrm{~km}$ are still present. In general, the $2 \mathrm{MeV}$ features are less obvious in the $\mathrm{O}_{3}$ composite, except for the positive $\mathrm{O}_{3}$ amplitudes above the hinted downward transport. Nevertheless, the agreement between Ap and $2 \mathrm{MeV}$ pattern is quite strong, in MIPAS observations in particular, although both parameters are only indirectly related to $\mathrm{O}_{3}$. However, the $\mathrm{O}_{3}$ structure associated to both indices is far too similar and additionally found in all three instruments to be a coincidence, even if the descending $\mathrm{O}_{3}$ response to $2 \mathrm{MeV}$ is weaker. Since Ap represents lower particle energy levels compared to the $2 \mathrm{MeV}$ and both indices are only moderately correlated (see Fig. 4), the similar results strongly indicate a related source mechanism, suggesting solar wind variability.

Considering the entire process, that energetic particles produce $\mathrm{NO}_{x}$ which eventually destroys stratospheric $\mathrm{O}_{3}$, the Ap impact observed in $\mathrm{O}_{3}$ (see Fig. 5) is expected to be reversed in $\mathrm{NO}_{\mathrm{x}}$, at least in the stratosphere. In order to investigate this in more detail, the analysis was repeated for 1 April Ap and $\mathrm{NO}_{\mathrm{x}}$. Here $\mathrm{NO}_{\mathrm{x}}$, is represented only by $\mathrm{NO}_{2}$ from MIPAS observations, because the respective $\mathrm{NO}$ measurements are quite noisy compared to $\mathrm{NO}_{2}$, especially below $30 \mathrm{~km}$. This is still reasonable because $\mathrm{NO}$ is converted to $\mathrm{NO}_{2}$ during night and therefore $\mathrm{NO}_{2}$ is the major fraction of $\mathrm{NO}_{\mathrm{x}}$ inside the Antarctic polar vortex. The corresponding results include the years 2005-2010 and are displayed in Fig. 6, supporting that the stratospheric $\mathrm{O}_{3}$ depletion can be indeed associated to the catalytic $\mathrm{NO}_{\mathrm{x}} / \mathrm{O}_{3}$ cycle. The Ap signal in $\mathrm{NO}_{2}$ is stronger by the factor of $2-5$, compared to the respective $\mathrm{O}_{3}$ amplitudes. The sharp gradient in mid July originates from $2005 \mathrm{NO}_{2}$ data, which are not available afterwards. However, the general structure of the subsiding Ap signal in $\mathrm{NO}_{2}$ is still similar with and without 2005 observations. Note that the essentially smaller $\mathrm{NO}_{2}$ amplitudes in October below the significance level of $95 \%$ are not in conflict with the respective well pronounced negative $\mathrm{O}_{3}$ response, because the latter one results from an accumulation effect from the $\mathrm{NO}_{2}$ above. Furthermore, large negative $\mathrm{NO}_{2}$ amplitudes throughout the entire winter below $\sim 30 \mathrm{~km}$ are observed, matching the high positive $\mathrm{O}_{3}$ response to Ap. A possible reason for this behaviour might be that $\mathrm{NO}_{2}$ is stored in reservoir species, like $\mathrm{ClONO}_{2}, \mathrm{HNO}_{3}$, and $\mathrm{N}_{2} \mathrm{O}_{5}$, due to reactions with $\mathrm{ClO}, \mathrm{OH}$, and $\mathrm{NO}_{3}$, respectively. However, $\mathrm{N}_{2} \mathrm{O}_{5}$ is converted to $\mathrm{HNO}_{3}$ via water ion cluster chemistry (López-Puertas et al., 2005, their reactions 1 and 8-12), which was also investigated with respect to EPP for conditions without solar proton events by Stiller et al. (2005). These reactions eventually lead to lower $\mathrm{NO}_{\mathrm{x}}$ concentrations, consequently slowing down the catalytic $\mathrm{O}_{3}$ depletion. Based on the corresponding MIPAS 


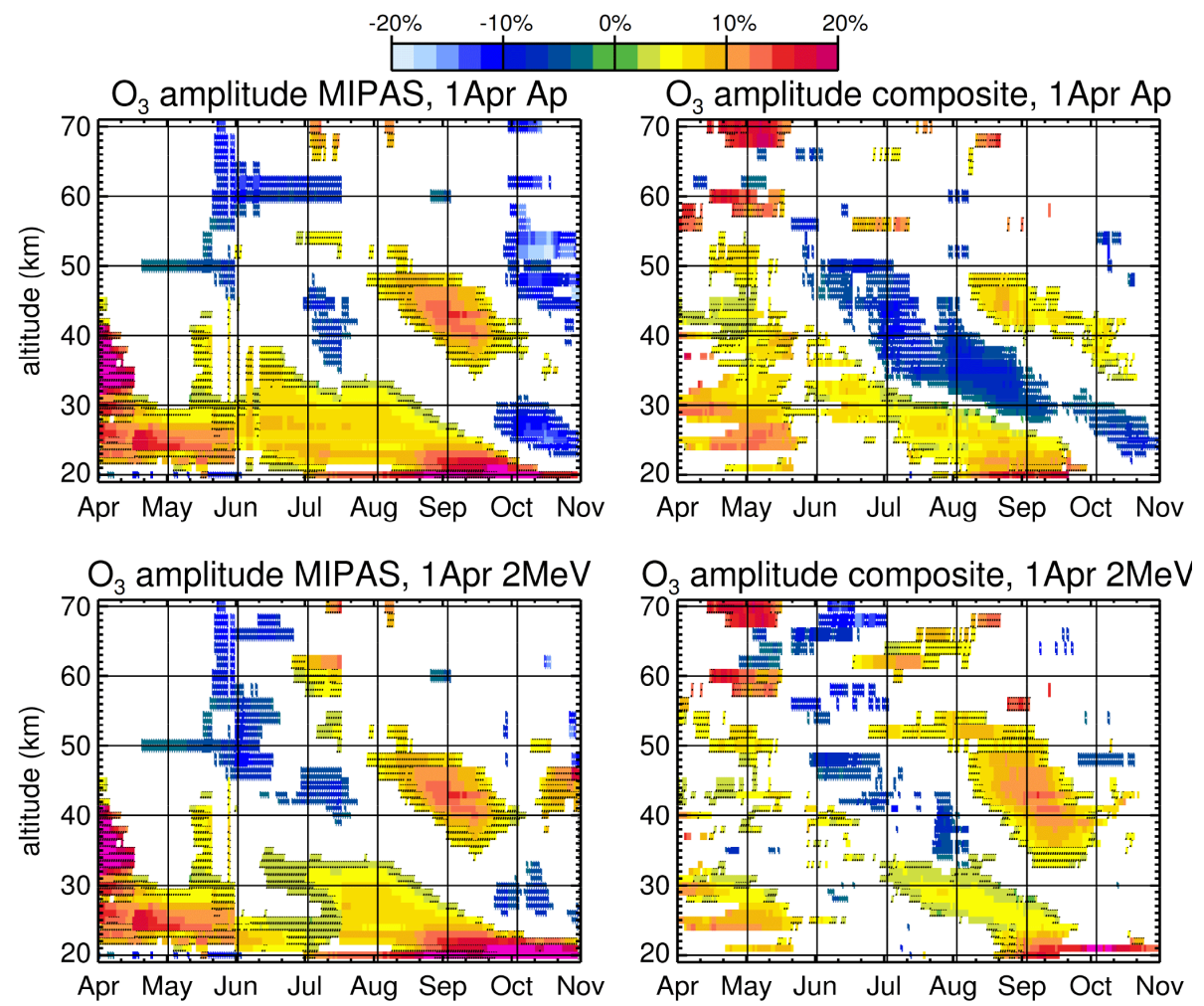

Figure 5. Same as Fig. 3 but only for Ap index (upper row) and $\geq 2 \mathrm{MeV}$ electron flux (lower row) from 2005 to 2010.

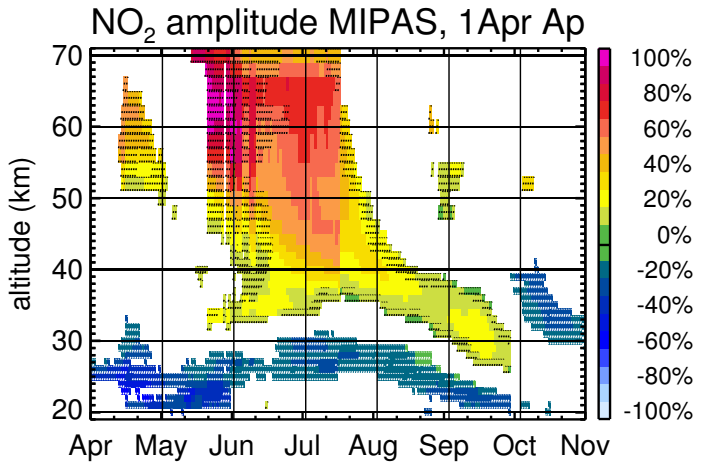

Figure 6. Same as Fig. 3, but only for the $\mathrm{NO}_{2}$ amplitude associated to 1 April Ap index. The $\mathrm{NO}_{2}$ was derived from MIPAS observations from 2005 to 2010.

climatologies (not shown here), $\mathrm{HNO}_{3}$ is more important until mid July, while $\mathrm{ClONO}_{2}$ is dominating afterwards and its influence becomes essentially crucial in spring due to heterogeneous chemistry which has taken place before. This suggested $\mathrm{NO}_{2}-\mathrm{ClONO}_{2}$ mechanism is supported by Whole Atmosphere Community Climate Model results reported by Jackman et al. (2009, their Figs. 6 and 7), who simulated the impact of the SPE in July 2000 on stratospheric $\mathrm{O}_{3}$ and $\mathrm{NO}_{y}$ $\left(=\mathrm{NO}_{\mathrm{x}}+\mathrm{NO}_{3}+\mathrm{N}_{2} \mathrm{O} 5+\mathrm{HNO}_{3}+\mathrm{HO}_{2} \mathrm{NO}_{2}+\mathrm{ClONO}_{2}+\right.$ $\mathrm{BrONO}_{2}$ ).
Furthermore, the positive $\mathrm{O}_{3}$ amplitudes below $\sim 30 \mathrm{~km}$ could be also partly explained by the self healing effect of $\mathrm{O}_{3}$ (Jackman and McPeters, 1985). Altitude regions of reduced $\mathrm{O}_{3}$ will lead to increased solar UV radiation in the layers directly below. This is accompanied by a higher production of atomic oxygen and would consequently increase the formation of $\mathrm{O}_{3}$. However, this proposed mechanism would only have an additional effect, contributing to the formation of $\mathrm{O}_{3}$ in the atmospheric layer right below the subsidence, but cannot account for the entire region. Note that this layer is also present throughout the entire winter, and thus an influence from the vortex above is unlikely but any further investigations are beyond the scope of this study.

Additionally, the area of high positive $\mathrm{Ap} / \mathrm{O}_{3}$ structure between 35 and $50 \mathrm{~km}$ from August to September cannot be completely explained by the $\mathrm{NO}_{\mathrm{x}} / \mathrm{O}_{3}$ cycle. In detail, the respective Ap influence of $\mathrm{NO}_{2}$ is close to 0 and consequently well below the $95 \%$, while the respective MIPAS $\mathrm{ClONO}_{2}$ amplitude (not shown here) reveals positive values, which are also mostly below the $95 \%$ significance level. These results are at least not in conflict with a higher $\mathrm{O}_{3}$ amplitude. Furthermore, this positive Ap impact on $\mathrm{O}_{3}$ is essentially less visible in the composite results than in MIPAS data, and a corresponding composite analysis for $\mathrm{Ap} / \mathrm{NO}_{2}$ is necessary for a more detailed investigation. But this is not possible due to non-existing $\mathrm{NO}_{2}$ measurements from SABER and SMR. Thus no definite explanation can be given at this stage and 


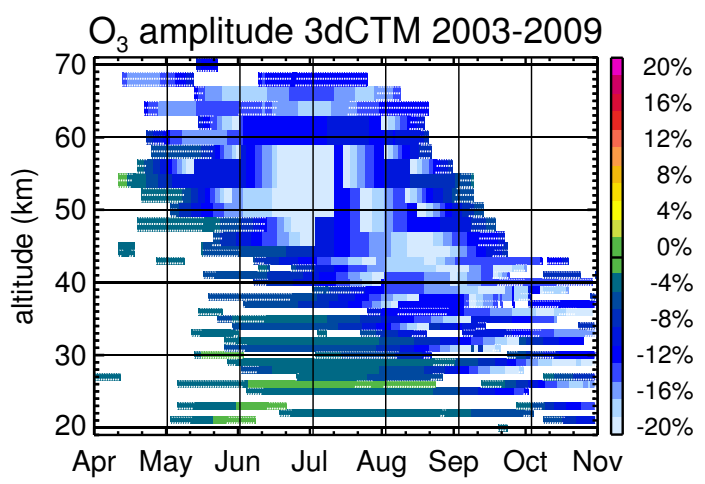

Figure 7. $\mathrm{O}_{3}$ amplitude (see Sect. 2.4 for definition), simulated by the 3dCTM from 2003 to 2009 . Shown are values above $95 \%$ significance level, according to a Student's $t$ test, and areas between 95 and $99 \%$ significance level are shaded.

this feature is a subject of a future work. However, it should be pointed out that this structure does not harm the underlying mechanism proposed to explain the identified negative $\mathrm{O}_{3}$ amplitude and subsequent downward transport.

\subsection{Comparison with 3dCTM}

The simulated $\mathrm{O}_{3}$ amplitude between the EP run and base run, representing high and low geomagnetic activity, respectively, is displayed in Fig. 7. Note that the modelled $\mathrm{O}_{3}$ amplitude is also referred to as $\mathrm{O}_{3}$ amplitude here, which is justified because "observed" and "modelled" $\mathrm{O}_{3}$ amplitude still hold the same physical meaning, even if the calculation algorithm is slightly different. It is reasonable to investigate the complete simulated time interval from 2003 to 2009, because the model runs represent solar minimum conditions similar to the years 2005-2010. The results reveal apparent negative $\mathrm{O}_{3}$ amplitudes propagating downwards throughout the winter with maximum negative values during midwinter between 45 and $60 \mathrm{~km}$. The subsidence shows larger negative $\mathrm{O}_{3}$ amplitudes compared to the measurements and is also much broader, which might be due to the constant F10.7 and the prescribed dynamics, both reducing the inter-annual variability of $\mathrm{O}_{3}$. Furthermore, we performed an on/off experiment, while in reality the EPP indirect effect is a persistent feature. Below $30 \mathrm{~km}$ the observed high positive $\mathrm{O}_{3}$ amplitudes associated with Ap are only indicated in the model results by essentially weaker and additionally negative amplitudes. However, the model amplitudes are at least less negative compared to the values above. The second positive region above the downwelling is completely missing. Further note that the strong positive response during late winter/early spring below $30 \mathrm{~km}$ might not be reproduced by the model due to missing heterogeneous chemistry. The proposed self healing effect of $\mathrm{O}_{3}$ (see Sect. 3.1.2) was also tested, using $\mathrm{O}^{1} \mathrm{D}$ as a proxy for the $\mathrm{O}_{3}$ photolysis rate in the Lyman-alpha band and calculating the $\mathrm{O}^{1} \mathrm{D}$ amplitude (not shown here).
However, the expected positive response directly below the downwelling is only partly visible and even below the $67 \%$ significance level.

The qualitative agreement between model results and observations in the stratosphere suggests that the subsiding Ap signal found in $\mathrm{O}_{3}$ is actually originating from particle precipitation. However, the simulated downwelling starts at altitudes $>60 \mathrm{~km}$ while observations reveal no obvious structures in the mesosphere, possibly caused by satellite sampling. As already stated in Sect 3.1.2, the mesospheric behaviour cannot be caused by $\mathrm{NO}_{\mathrm{x}}$, because the $\mathrm{NO}_{\mathrm{x}} / \mathrm{O}_{3}$ cycle is not efficiently working at these altitudes. Thus the $\mathrm{O}_{3}$ depletion $>50 \mathrm{~km}$ could be accounted to $\mathrm{OH}$ production, which is most likely overestimated in the model and consequently leads to an increased $\mathrm{O}_{3}$ depletion not observed by the satellite instruments.

\section{Conclusions}

We have investigated the $\mathrm{O}_{3}$ behaviour inside the Antarctic polar vortex from 2002 to 2011, observed by three independent satellite based instruments ENVISAT/MIPAS, Odin/SMR, and TIMED/SABER. These $\mathrm{O}_{3}$ vmr measurements, based on 26-day running means from 1 April to 1 November covering altitudes from 20 to $70 \mathrm{~km}$, were individually grouped into high and low index activity according to the 26-day averages centred around 1 April, 1 May, and 1 June of different solar and geomagnetic indices (F10.7, Ap, $2 \mathrm{MeV}$ ). After minimising the direct influence of the solar radiation by only considering the period of solar minimum activity from 2005 to 2010 we found a negative $\mathrm{O}_{3}$ response caused by geomagnetic activity (Ap) from 1 April in all three instruments, ranging from -5 to $-10 \%$ and propagating downwards throughout the Antarctic winter from $\sim 50 \mathrm{~km}$ down to $\sim 25 \mathrm{~km}$. This subsiding negative signal in $\mathrm{O}_{3}$ is above the significance level of $95 \%$ and overlaps with the corresponding positive $\mathrm{NO}_{2}$ response to 1 April Ap, supporting that $\mathrm{NO}_{\mathrm{x}}$ is indeed the cause of the $\mathrm{O}_{3}$ depletion. We could also show that the high positive $\mathrm{O}_{3}$ response below $30 \mathrm{~km}$, which is present during the entire winter, is in agreement with respective negative $\mathrm{NO}_{2}$ structures. The cause of the $\mathrm{NO}_{2}$ behaviour is possibly related to the formation of the reservoir species $\mathrm{ClONO}_{2}$ and $\mathrm{HNO}_{3}$, slowing down the catalytic destruction of $\mathrm{O}_{3}$ by $\mathrm{Cl}$. The $\mathrm{O}_{3}$ pattern induced by the magnetosphere $(2 \mathrm{MeV})$ from 1 April are similar but weaker, compared to the respective geomagnetic activity, still suggesting a related source mechanism between $2 \mathrm{MeV}$ and Ap like solar wind variability. The composite observations of all three instruments are in good qualitative agreement with 3dCTM simulation, revealing similar $\mathrm{O}_{3}$ pattern induced by the geomagnetic activity from 1 April while the simulated $\mathrm{O}_{3}$ response is larger but still in the same order of magnitude.

However, we have to point out that the validity of the subsiding $\mathrm{O}_{3}$ depletion associated to geomagnetic activity and 
$\mathrm{NO}_{\mathrm{x}}$ is not ensured due to the short time series of only 6 years at most. Thus, we conclude that precipitating particles are strongly indicated as a factor contributing to stratospheric $\mathrm{O}_{3}$ during Antarctic winter, but we cannot prove the link unambiguously.

Author contributions. T. Fytterer, analysed the satellite and indices data and wrote the final script. G. Stiller, J. Urban and K. Pérot, and M. Mlynczak provided the $\mathrm{O}_{3}$ data from ENVISAT/MIPAS, Odin/SMR, and TIMED/SABER, respectively, and all of them contributed to interpretation. H. Nieder performed the 3dCTM simulations. M. Sinnhuber initiated the study and contributed to interpretation.

Acknowledgements. T. Fytterer, H. Nieder, and M. Sinnhuber gratefully acknowledge funding by the Helmholtz Association of German Research Centres (HGF), grant VH-NG-624. The authors also acknowledge support by Deutsche Forschungsgemeinschaft and Open Access Publishing Fund of Karlsruhe Institute of Technology. Odin is a Swedish-led satellite project funded jointly by the Swedish National Space Board (SNSB), the Canadian Space Agency (CSA), the National Technology Agency of Finland (Tekes), the Centre National d'Etudes Spatiales (CNES) in France and the third party mission program of the European Space Agency (ESA). We further like to thank the ERA-Interim for free provision of data and related support.

Edited by: Q. Errera

\section{References}

Azeem, S. M. I., Talaat, E. R., Sivjee, G. G., and Yee, J.-H.: Mesosphere and lower thermosphere temperature anomalies during the 2002 Antarctic stratospheric warming event, Ann. Geophys., 28, 267-276, doi:10.5194/angeo-28-267-2010, 2010.

Berger, U.: Modeling of middle atmosphere dynamics with LIMA, J. Atmos. Sol.-Terr. Phys., 70, 1170-1200, doi:10.1016/j.jastp.2008.02.004, 2008.

Eckert, E., von Clarmann, T., Kiefer, M., Stiller, G. P., Lossow, S., Glatthor, N., Degenstein, D. A., Froidevaux, L., GodinBeekmann, S., Leblanc, T., McDermid, S., Pastel, M., Steinbrecht, W., Swart, D. P. J., Walker, K. A., and Bernath, P. F.: Drift-corrected trends and periodic variations in MIPAS IMK/IAA ozone measurements, Atmos. Chem. Phys., 14, 25712589, doi:10.5194/acp-14-2571-2014, 2014.

Fischer, H., Birk, M., Blom, C., Carli, B., Carlotti, M., von Clarmann, T., Delbouille, L., Dudhia, A., Ehhalt, D., Endemann, M., Flaud, J. M., Gessner, R., Kleinert, A., Koopman, R., Langen, J., López-Puertas, M., Mosner, P., Nett, H., Oelhaf, H., Perron, G., Remedios, J., Ridolfi, M., Stiller, G., and Zander, R.: MIPAS: an instrument for atmospheric and climate research, Atmos. Chem. Phys., 8, 2151-2188, doi:10.5194/acp-8-2151-2008, 2008.

Funke, B., López-Puertas, M., von Clarmann, T., Stiller, G. P., Fischer, H., Glatthor, N., Grabowski, U., Höpfner, M., Kellmann, S., Kiefer, M., Linden, A., Mengistu Tsidu, G., Milz, M.,
Steck, T., and Wang, D. Y.: Retrieval of stratospheric $\mathrm{NO}_{\mathrm{x}}$ from 5.3 and $6.2 \mu \mathrm{m}$ nonlocal thermodynamic equilibrium emissions measured by Michelson Interferometer for Passive Atmospheric Sounding (MIPAS) on Envisat, J. Geophys. Res., 110, D09302, doi:10.1029/2004JD005225, 2005.

Funke, B., Baumgaertner, A., Calisto, M., Egorova, T., Jackman, C. H., Kieser, J., Krivolutsky, A., López-Puertas, M., Marsh, D. R., Reddmann, T., Rozanov, E., Salmi, S.-M., Sinnhuber, M., Stiller, G. P., Verronen, P. T., Versick, S., von Clarmann, T., Vyushkova, T. Y., Wieters, N., and Wissing, J. M.: Composition changes after the "Halloween" solar proton event: the High Energy Particle Precipitation in the Atmosphere (HEPPA) model versus MIPAS data intercomparison study, Atmos. Chem. Phys., 11, 90899139, doi:10.5194/acp-11-9089-2011, 2011.

Funke, B., López-Puertas, M., Stiller, G. P., and von Clarmann, T.: Mesospheric and stratospheric $\mathrm{NO}_{\mathrm{y}}$ produced by energetic particle precipitation during 2002-2012, J. Geophys. Res-Atmos., 119, 4429-4446, doi:10.1002/2013JD021404, 2014.

Glatthor, N., von Clarmann, T., Fischer, H., Funke, B., GilLópez, S., Grabowski, U., Höpfner, M., Kellmann, S., Linden, A., López-Puertas, M., Mengistu Tsidu, G., Milz, M., Steck, T., Stiller, G. P., and Wang, D.-Y.: Retrieval of stratospheric ozone profiles from MIPAS/ENVISAT limb emission spectra: a sensitivity study, Atmos. Chem. Phys., 6, 2767-2781, doi:10.5194/acp-6-2767-2006, 2006.

Gray, L. J., Beer, J., Geller, M., Haigh, J. D., Lockwodd, M., Matthes, K., Cubasch, U., Fleitmann, D., Harrison, G., Hood, L., Luterbacher, J., Meehl, G. A., Shindell, D., van Geel, B., and White, W.: Solar influences on climate, Rev. Geophys., 48, RG4001, doi:10.1029/2009RG000282, 2010.

Jackman, C. H. and McPeters, R. D.: The Response of Ozone to Solar Proton Events During Solar Cycle 21: A Theoretical Interpretation, J. Geophys. Res., 90, 7955-7966, 1985.

Jackman, C. H., DeLand, M. T., Labow, G. J., Fleming, E. L., Weisenstein, D. K., Ko, M. K. W., Sinnhuber, M., and Russell III, J. M.: Neutral atmospheric influences of the solar proton events in October-November 2003, J. Geophys. Res., 110, A09S27, doi:10.1029/2004JA010888, 2005.

Jackman, C. H., Marsh, D. R., Vitt, F. M., Garcia, R. R., Randall, C. E., Fleming, E. L., and Frith, S. M.: Long-term middle atmospheric influence of very large solar proton events, J. Geophys. Res., 114, D11304, doi:10.1029/2008JD011415, 2009.

Lary, D. J.: Catalytic destruction of stratospheric ozone, J. Geophys. Res., 102, 21515-21526, doi:10.1029/97JD00912, 1997.

López-Puertas, M., Funke, B., Gil-López, S., von Clarmann, T., Stiller, G. P., Höpfner, M., Kellmann, S., Mengistu Tsidu, G., Fischer, H., and Jackman, C. H.: $\mathrm{HNO}_{3}, \mathrm{~N}_{2} \mathrm{O}_{5}$, and $\mathrm{ClONO}_{2}$ enhancements after the October-November 2003 solar proton events, J. Geophys. Res., 110, A09S44, doi:10.1029/2005JA011051, 2005.

Murtagh, D., Frisk, U., Merino, F., Ridal, M., Jonsson, A., Stegman, J., Witt, G., Eriksson, P., Jiménez, C., Megie, G., de la Noë, J., Ricaud, P., Baron, P., Pardo, J. R., Hauchcorne, A., Llewellyn, E. J., Degenstein, D. A., Gattinger, R. L., Lloyd, N. D., Evans, W. F. J., McDade, I. C., Haley, C. S., Sioris, C., von Savigny, C., Solheim, B. H., McConnell, J. C., Strong, K., Richardson, E. H., Leppelmeier, G. W., Kyrölä, E., Auvinen, H., and Oikarinen, L.: An overview of the Odin atmospheric mission, Can. J. Phys., 80, 309-319, doi:10.1139/p01-157, 2002. 
Nash, E. R., Newman, P. A., Rosenfield, J. E., and Schoeberl, M. R.: An objective determination of the polar vortex using Ertel's potential vorticity, J. Geophys. Res., 101, 9471-9478, doi:10.1029/96JD00066, 1996.

Nieder, H., Winkler, H., Marsh, D. R., and Sinnhuber, M.: NO $\mathrm{NO}_{\mathrm{x}}$ production due to energetic particle precipitation in the MLT region: Results from ion chemistry model studies, J. Geophys. Res.Space., 119, 2137-2148, doi:10.1002/2013JA019044, 2014.

Porter, H. S., Jackman, C. H, and Green, A. E. S.: Efficiencies for production of atomic nitrogen and oxygen by relativistic proton impact in air, J. Chem. Phys., 65, 154-167, doi:10.1063/1.432812, 1976.

Prather, M.: Numerical advection by conservation of secondorder moments, J. Geophys. Res., 91, 6671-6681, doi:10.1029/JD091iD06p06671, 1986.

Preusse, P., Eckermann, S. D., Ern, M., Oberheide, J., Picard, R. H., Roble, R. M., Riese, M., Russell III, J. M., and Mlynczak, M. G.: Global ray tracing simulations of the SABER gravity wave climatology, J. Geophys. Res., 114, D08126, doi:10.1029/2008JD011214, 2009.

Randall, C. E., Rusch, D. W., Bevilacqua, R. M., and Hoppel, K. W.: Polar Ozone And Aerosol Measurement (POAM) II stratospheric $\mathrm{NO}_{2}$, 1993-1996, J. Geophys. Res., 103, 28361-28371, doi:10.1029/98JD02092, 1998.

Randall, C. E., Harvey, V. L., Singleton, C. S., Bailey, S. M., Bernath, P. F., Codrescu, M., Nakajima, H., and Russell III, J. M.: Energetic particle precipitation effects on the Southern Hemisphere stratosphere in 1992-2005, J. Geophys. Res., 112, D08308, doi:10.1029/2006JD007696, 2007.

Reddmann, T., Ruhnke, R., Versick, S., and Kouker, W.: Modeling disturbed stratospheric chemistry during solar-induced $\mathrm{NO}_{\mathrm{x}}$ enhancements observed with MIPAS/ENVISAT, J. Geophys. Res., 115, D00I11, doi:10.1029/2009JD012569, 2010.

Rodger, C. J., Kavanagh, A. J., Clilverd, M. A., and Marple, S. R.: Comparison between POES energetic electron precipitation observations and riometer absorptions: Implications for determining true precipitation fluxes, J. Geophys. Res.-Space., 118, 78107821, doi:10.1002/2013JA019439, 2013.

Rong, P. P., Russell III, J. M., Mlynczak, M. G., Remsberg, E. E., Marshall, B. T., Gordley, L. L., and López-Puertas, M.: Validation of Thermosphere Ionosphere Mesosphere Energetics and Dynamics/Sounding of the Atmosphere using Broadband Emission Radiometry (TIMED/SABER) v1.07 ozone at $9.6 \mu \mathrm{m}$ in altitude range 15-70 km, J. Geophys. Res., 114, D04306, doi:10.1029/2008JD010073, 2009.

Rusch, D. W., Gerard, J. C., Solomon, S., Crutzen, P. J., and Reid, G. C.: The effect of particle precipitation events on the neutral and ion chemistry of the middle atmosphere - I. Odd nitrogen, Planet. Space Sci., 29, 767-774, doi:10.1016/0032-0633(81)90048-9, 1981.

Sinnhuber, M., Kazeminejad, S., and Wissing, J. M.: Interannual variation of $\mathrm{NO}_{\mathrm{x}}$ from the lower thermosphere to the upper stratosphere in the years 1991-2005, J. Geophys. Res., 116, A02312, doi:10.1029/2010JA015825, 2011.

Sinnhuber, M., Nieder, H., and Wieters, N.: Energetic particles precipitation and the chemistry of the mesosphere/lower thermosphere, Surv. Geophys., 33, 1281-1334, doi:10.1007/s10712012-9201-3, 2012.
Solomon, S., Rusch, D. W., Gerard, J. C., Reid, G. C., and Crutzen, P. J.: The effect of particle precipitation events on the neutral and ion chemistry of the middle atmosphere: II. odd hydrogen, Planet. Space Sci., 29, 885-892, doi:10.1016/00320633(81)90078-7, 1981.

Solomon, S., Crutzen, P. J., and Roble, R. G.: Photochemical coupling between the thermosphere and the lower atmosphere 1. odd nitrogen from 50 to $120 \mathrm{~km}$, J. Geophys. Res., 87, 7206-7220, doi:10.1029/JC087iC09p07206, 1982.

Steck, T., von Clarmann, T., Fischer, H., Funke, B., Glatthor, N., Grabowski, U., Höpfner, M., Kellmann, S., Kiefer, M., Linden, A., Milz, M., Stiller, G. P., Wang, D. Y., Allaart, M., Blumenstock, Th., von der Gathen, P., Hansen, G., Hase, F., Hochschild, G., Kopp, G., Kyrö, E., Oelhaf, H., Raffalski, U., Redondas Marrero, A., Remsberg, E., Russell III, J., Stebel, K., Steinbrecht, W., Wetzel, G., Yela, M., and Zhang, G.: Bias determination and precision validation of ozone profiles from MIPAS-Envisat retrieved with the IMK-IAA processor, Atmos. Chem. Phys., 7, 3639-3662, doi:10.5194/acp-7-3639-2007, 2007.

Stiller, G. P., Tsidu, G. M., von Clarmann, T., Glatthor, N., Höpfner, M., Kellmann, S., Linden, A., Ruhnke, R., Fischer, H., López-Puertas, M., Funke,„B., and Gil-López, S.: An enhanced $\mathrm{HNO}_{3}$ second maximum in the Antarctic midwinter upper stratosphere 2003, J. Geophys. Res, 110, D20303, doi:10.1029/2005JD006011, 2005.

Urban, J., Lautié, N., Le Flochmoën, E., Jiménez, C., Eriksson, P., de La Noë, J., Dupuy, E., Ekström, M., El Amraoui, L., Frisk, U., Murtagh, D., Olberg, M., and Ricaud, P.: Odin/SMR limb observations of stratospheric trace gases: Level 2 processing of $\mathrm{ClO}, \mathrm{N}_{2} \mathrm{O}, \mathrm{HNO}_{3}$, and $\mathrm{O}_{3}$, J. Geophys. Res., 110, D14307, doi:10.1029/2004JD005741, 2005.

Von Clarmann, T., Glatthor, N., Grabowski, U., Höpfner, M., Kellmann, S., Kiefer, M., Linden, A., Mengistu Tsidu, G., Milz, M., Steck, T., Stiller, G. P., Wang, D. Y., Fischer, H., Funke, B., Gil-López, S., and López-Puertas, M.: Retrieval of temperature and tangent altitude pointing from limb emission spectra recorded from space by the Michelson Interferometer for Passive Atmospheric Sounding (MIPAS), J. Geophys. Res., 108, 4736, doi:10.1029/2003JD003602, 2003.

von Clarmann, T., Höpfner, M., Kellmann, S., Linden, A., Chauhan, S., Funke, B., Grabowski, U., Glatthor, N., Kiefer, M., Schieferdecker, T., Stiller, G. P., and Versick, S.: Retrieval of temperature, $\mathrm{H}_{2} \mathrm{O}, \mathrm{O}_{3}, \mathrm{HNO}_{3}, \mathrm{CH}_{4}, \mathrm{~N}_{2} \mathrm{O}, \mathrm{ClONO}_{2}$ and $\mathrm{ClO}$ from MIPAS reduced resolution nominal mode limb emission measurements, Atmos. Meas. Tech., 2, 159-175, doi:10.5194/amt-2-159-2009, 2009.

Wissing, J. M. and Kallenrode, M. B.: Atmospheric Ionization Module Osnabrück (AIMOS): a 3-D model to determine atmospheric ionization by energetic charged particles from different populations, J. Geophys. Res., 114, A06104, doi:10.1029/2008JA013884, 2009.

Wissing, J. M., Kallenrode, M. B., Wieters, N., Winkler, H., and Sinnhuber, M.: Atmospheric Ionization Module Osnabrück (AIMOS): 2. Total particle inventory in the October-November 2003 event and ozone, J. Geophys. Res., 115, A02308, doi:10.1029/2009JA014419, 2010. 